\title{
Educação de Jovens e Adultos e representações sociais: um estudo psicossocial entre estudantes da EJA
}

\author{
Youth and Adults Education and social representations: psychosocial study \\ among EJA students
}

\section{Educación de Jóvenes y Adultos y representaciones sociales: estudio psicosocial entre estudiantes de la EJA}

\author{
Carolina Martins Moraes ${ }^{1}$ \\ Ludgleydson Fernandes de Araújo ${ }^{1}$ \\ Fauston Negreiros ${ }^{1}$
}

Recebido em: 13/12/2018. Revisado e aprovado em: 19/06/2019. Aceito em: 04/07/2019. DOI: http://dx.doi.org/10.20435/inter.v21i3.2312

\begin{abstract}
Resumo: Este estudo objetivou apreender as representações sociais (RSs) de estudantes da Educação de Jovens e Adultos (EJA) acerca da escola, da própria modalidade "educação de jovens e adultos" e do futuro. Os resultados indicaram que a RS da escola é ancorada à aquisição de conhecimento e também à socialização. A EJA é tida como uma oportunidade de concluir os estudos, de obter conhecimento e uma formação. $O$ futuro por vezes é representado pela família, trabalho, possibilidade de emprego, casar e cuidar dos filhos.

Palavras-chave: escola; Educação de Jovens e Adultos; representações sociais.

Abstract: This study aimed at apprehending the social representations (RSs) of students of Youth and Adult Education (EJA) about the school, the modality "youth and adult education" itself, and the future. The results indicated that the RS of the school is anchored to the acquisition of knowledge and the socialization. The EJA is an opportunity to complete the studies, obtain knowledge, and training. The future, by several times, is represented by family, work, the possibility of employment, marriage, and care of children.

Keywords: school; Youth and Adult Education; social representations.

Resumen: Este estudio objetivó aprehender las representaciones sociales (RSs) de estudiantes de la Educación de Jóvenes y Adultos (EJA) acerca de la escuela, de la propia modalidad "educación de jóvenes y adultos" y del futuro. Los resultados indicaron que la RS de la escuela está anclada a la adquisición de conocimiento y también a la socialización. La EJA se considera como una oportunidad de concluir los estudios, de obtener conocimiento y una formación. El futuro, por su vez, es representado por la familia, trabajo, posibilidad de empleo, casarse y cuidar de los hijos.
\end{abstract}

Palabras clave: escuela; Educación de Jóvenes y Adultos; representaciones sociales.

\section{INTRODUÇÃO}

A Educação de Jovens e Adultos (EJA) é uma modalidade da educação básica destinada a jovens e adultos que não iniciaram a escolarização ou que se encontram com a escolarização incompleta, seja porque deixaram a escola por diversos motivos, seja por terem enfrentado sucessivas reprovações (BRASIL, 2010). Tem o intuito de saldar uma dívida social do Estado para com os cidadãos que tiveram o direito à educação negado. Destina-se, assim, àqueles que se encontram na faixa etária superior à considerada própria para os níveis de conclusão do Ensino Fundamental e do Ensino Médio, de acordo com o Parecer n. 11/2000 de 10 de maio de 2000 (BRASIL, 2000).

Para compreender as configurações atuais da EJA, é importante o entendimento de como a escola foi se constituindo enquanto espaço social e de formação, aliada ao contexto econômico

\footnotetext{
${ }^{1}$ Universidade Federal do Piauí (UFPI), Parnaíba, Piauí, Brasil.
} 
e político, e ainda como as práticas educativas voltadas para a população adulta foram se desenvolvendo ao logo dos anos. Nesse sentido, Leite (2007, ao realizar uma síntese histórica das políticas educacionais no país, destaca marcos importantes, descritos a seguir.

Para o autor supracitado, a década de 1930 é marcada pela implantação da produção industrial no país. Houve mudanças substanciais nas dimensões sociais e políticas, como: mudança dos latifúndios agrícolas para burguesia industrial, a constituição da classe operária composta por trabalhadores urbanos e rurais, e a crescente intervenção do Estado. No âmbito da educação, as Constituições de 1934 e de 1937 marcam o direcionamento do sistema educacional para a profissionalização da mão de obra e o controle ideológico. Nas décadas subsequentes, as políticas educacionais direcionaram-se para atender às demandas industriais, o que culminou na elaboração da Lei de Diretrizes e Bases da Educação e na implantação dos sistemas "S" (Senai e Senac); apesar disso, metade da população ainda não tinha acesso à educação e o ensino público era eletivo.

Este mesmo cenário foi palco das primeiras ações formativas voltadas à população adulta. Passaram a ser propagadas em todo o país campanhas de alfabetização de curta duração cujo objetivo era reduzir os altos índices de analfabetismo decorrentes da exclusão do sistema educacional, iniciando, com isso, as primeiras práticas de educação para adultos. Podem ser citadas: Campanha de Educação de Adultos em 1947, a Campanha de Educação Rural em 1952, e a Campanha de Erradicação do Analfabetismo em 1958 (DI PIERRO, 2005; GOMES, 2015; HADDAD; DI PIERRO, 2000; HADDAD, 2007; PEREIRA, 2014).

No início da década de 1960, segundo Silva (2017), proliferaram-se ações de educação popular que aliavam práticas pedagógicas à formação política, visando à conscientização dos estudantes quanto às relações sociais existentes. Emergiram, nas mais diversas regiões do país, ações educativas direcionadas às classes populares, entre as quais se pode mencionar: os Centros de Cultura Popular (CPC), os programas de alfabetização encabeçados por Paulo Freire, "De pé no chão também se aprende a ler" e "40 horas em quatro", e o Movimento Eclesial de Base, organizado pela Igreja Católica.

No mesmo período, contudo, houve o golpe militar e, de acordo com Leite (2007, a forte influência do capital estrangeiro culminou em mudanças não só na economia como na educação. A ênfase no avanço tecnológico, no incentivo ao mercado consumidor e na exportação tem por consequência a concentração de renda, exploração dos trabalhadores e cerceamento de inciativas de organização popular e política. As políticas educacionais passaram a atender aos interesses econômicos e ideologias vigentes, pois, embora a oferta do Ensino Fundamental e do Ensino Superior tenha sido ampliada, garantia-se aos cidadãos apenas a formação mínima para qualificação da sua mão e obra.

Além disso, para Gomes (2015), o governo passou a substituir as ações de educação popular desenvolvidas até então por programas de cunho assistencialista e conservador. Há a implantação do Movimento Brasileiro de Alfabetização de Jovens e Adultos (Mobral) para fins de erradicar o analfabetismo e dar continuidade à educação de adultos, contudo ele se detinha apenas em instrumentalizar os alunos quanto à leitura e escrita de forma descontextualizada. Apesar do exposto, as políticas educacionais implantadas no período pouco mudaram o quadro nacional, havendo ainda um número expressivo de analfabetos, crianças sem escolas e altos índices de reprovação entre os alunos da rede pública.

Com o fim desse período e a extinção do Mobral, os anos que se sucedem, segundo Pereira (2014), são "divisores de águas" para a EJA no país, pois uma série de dispositivos legais e políticas 
educacionais passaram a ser articulados e atualizados. Com a promulgação da Constituição de 1988, a educação passou a ser um direito de todos e dever do Estado; com isso, foi consolidado o compromisso do Estado com a educação, firmado junto à Organização das Nações Unidas (ONU) por meio da Declaração de Jomtien (LIBÂNEO, 2012).

A Declaração de Jomtien, também denominada de "Declaração Mundial da Conferência de Jomtien", foi um documento histórico produzido na Conferência Mundial sobre Educação para Todos, realizada em 1990, em Jomtien, na Tailândia, organizada e patrocinada pelo Banco Mundial. Essa declaração, na qual o Brasil foi signatário, e outros documentos produzidos nas demais conferências posteriores tiveram influência direta na educação brasileira, pois desses derivou-se uma série de políticas educacionais. Segundo Libâneo (2012), os princípios instituídos estiveram presentes na formulação de documentos como o Plano Decenal de Educação para Todos (1993-2003), elaborado no Governo Itamar Franco. Em seguida, nas diretrizes para a educação do Governo FHC (1995-1998; 1999-2002) e do Governo Lula (2003-2006; 2007-2010), na Lei de Diretrizes e Bases (Lei n. 9.394/96) e nas inciativas voltadas para universalização do acesso escolar, financiamento e repasse de recursos financeiros, descentralização da gestão, Parâmetros Curriculares Nacionais (PCN), ensino a distância, sistema nacional de avaliação, políticas do livro didático, entre outras.

Em relação à EJA, a Lei das Diretrizes e Bases da Educação (LDB), Lei n. 9396/1996, por sua vez, que lançou as diretrizes para educação nacional, trouxe o reconhecimento da EJA como modalidade de ensino da educação básica, muito embora ainda de maneira superficial. Um ponto nefasto da lei, contudo, é a redução da idade mínima para exames supletivos no Ensino Fundamental e Médio, bem como a diferenciação entre ensino regular e supletivo como dois segmentos da Ensino Básico Comum (DI PIERRO, 2005).

Com a virada do século XX, de acordo com Franchi e Günther (2018), um conjunto de ações e políticas voltadas para a modalidade passaram a ser implantadas visando estimular a escolarização e preparação do público jovem e adulto para o trabalho. Entre essas, podem ser citados: a criação da Secretaria de Alfabetização e Diversidade (Secad), o Programa Nacional de Inclusão de Jovens - Educação, Qualificação e Ação Comunitária (Projovem), o Programa Nacional de Integração da Educação Profissional com a Educação Básica na Modalidade de Jovens e Adultos (Proeja) e o Programa Nacional de Acesso ao Ensino Técnico e Emprego (Pronatec); apesar disso, a maneira como são articuladas essas ações e políticas revela que a EJA continua assumindo um lugar secundário nas políticas educacionais brasileiras.

O cenário descrito é importante para o entendimento de como ao longo dos anos a EJA foi sendo constituída até as configurações atuais, e não somente isso, auxilia também na compreensão das representações sociais construída por distintos grupos acerca da modalidade. Nesse sentido, diversos estudos (GOUVEIA; SILVA, 2015; NAIFF; NAIFF, 2008) foram realizados com vista a apreender as representações sociais (RSs) da EJA retratando como diferentes atores sociais representam a modalidade em determinados tempos e realidades distintas.

Este estudo, por sua vez, pautado na Teoria das Representações Sociais, parte da compreensão de Moscovici (2007) de que os indivíduos representam o mundo a sua volta e também o criam, pois vão além do que apenas perceber os estímulos e respondê-los, são marcados em suas representações por diferentes elementos (imagens, ideias e opiniões e outros) que atravessam suas experiências e cruzam gerações (ARAÚJO; CASTRO; SANTOS, 2018; CAMARGO; SCHLOSSER; GIACOMOZZI, 2018). 
Nessa direção, Jodelet (1989) descreve as RSs como um saber prático, um processo entre o mundo e as coisas, que emerge da necessidade de compreender, interpretar, tomar posição ante certos assuntos, levando a uma comunicação social em busca de assimilar novos conhecimentos e do desenvolvimento individual e coletivo (CARLOS; SANTOS; ARAUJO, 2018). As RSs correspondem, portanto, ao retrato de uma realidade social e do sentido partilhado por dado grupo; busca compreender as relações interpessoais e um dado fenômeno no contexto que ele ocorre, tendo, assim, uma abordagem psicossocial (SANTOS; MORAIS; NETO, 2012).

Diante do exposto, a compreensão da EJA em uma dimensão psicossocial e as representações partilhadas pelo grupo de estudantes da modalidade são relevantes, pois contribuem para o conhecimento da realidade social desses alunos, suas expectativas e anseios ante o processo de escolarização e, além disso, para o fomento de políticas educacionais adequadas ao contexto sociocultural desse público. O presente estudo objetivou, com isso, apreender as representações sociais de estudantes da EJA acerca da escola, da própria modalidade "educação de jovens e adultos" e do futuro.

\section{ASPECTOS METODOLÓGICOS}

\subsection{Tipo de estudo}

Trata-se de um estudo exploratório e descritivo, de abordagem qualitativa com dados transversais.

\subsection{Participantes}

Contou com a participação de 100 estudantes da modalidade EJA (ver Tabela 1). A quantidade de participantes foi estabelecida a partir da constatação objetiva do ponto de saturação, verificado com base no aparecimento e na frequência dos temas e enunciados. Segundo Fontanella et al. (2011), esse é o ponto de fechamento por exaustão que permite ao pesquisador inferir que novos elementos para subsidiar a teorização não precisam ser mais depreendidos do campo de observação.

Os participantes consistiram em alunos matriculados em um Centro de Educação de Jovens e Adultos (Cejas) localizado no município de Parnaíba, no Estado do Piauí. Os Cejas consistem em instituições de ensino público que ofertam o Ensino Fundamental e Ensino Médio na modalidade Educação de Jovens e Adultos, para alunos maiores de 18 anos. O curso é presencial e com disciplinas semestrais que variam quanto a sua carga horária, seguindo os parâmetros estabelecidas pela Resolução do Conselho Nacional de Educação n. 3, de 15 de junho de 2010 (BRASIL, 2010).

Foram estabelecidos como critérios de inclusão: estar regularmente matriculado e frequentando a instituição onde o estudo foi realizado; e como critério de exclusão: não ser aluno do referido centro ou não frequentar regularmente a escola.

\subsection{Instrumentos}

Para coletar as informações, foi elaborado um questionário para identificar o perfil sociodemográfico dos estudantes, com itens sobre idade, sexo, estado civil, quantidade de filhos e profissão. Foi utilizado também o Teste de Associação Livre de Palavras (Talp), empregado 
da seguinte forma: foi solicitado aos participantes que escrevessem cinco palavras eliciadas a partir das palavras-estímulo "escola", "educação de jovens e adultos" e "futuro" e, em seguida, enumerassem as palavras de 1 a 5 por ordem de importância, segundo sua opinião. A sistematização dos instrumentos foi realizada com base em um estudo prévio realizado por Negreiros et al. (2017).

\subsection{Procedimentos éticos e de coleta de dados}

O presente estudo seguiu os preceitos éticos estabelecidos pela Resolução n. 510/2016, do Conselho Nacional de Saúde (CNS), e contou com a anuência prévia da instituição. A partir disso, foi feito contato com a direção da escola para verificar a disponibilidade da instituição para realização da presente pesquisa. Em seguida, foi mantido contato com os alunos para informar os objetivos da pesquisa e que a participação era facultativa. Mediante aceite, foram dadas as instruções necessárias para o preenchimento dos instrumentos. Os dados foram coletados em situação coletiva de sala de aula, com grupos de estudantes que variou de 5 a 30 pessoas e com equipe de três pesquisadores previamente treinados e qualificados para essa tarefa. Foi assegurado aos alunos, portanto, o suporte necessário para o preenchimento das informações e o livre-arbítrio para participar ou não da referida pesquisa. Não foi observada nenhuma recusa em participar por parte dos alunos.

\subsection{Procedimentos de análise de dados}

A análise das informações obtidas se deu à luz da teoria das redes semânticas que estabelece três procedimentos para análise: o Peso Semântico (PS), o Núcleo da Rede (NR) e a Distância Semântica Quantitativa (DSQ). O peso semântico é calculado por meio das frequências das palavras evocadas conforme sua hierarquização de importância. Em seguida, a primeira palavra da ordem hierárquica é multiplicada por 5; a segunda, por 4; a terceira, por 3; a quarta, por 2; e a quinta e última, por 1 , respectivamente. Obtidas essas palavras, é possível definir o NR; em seguida, a distância semântica entre as palavras do núcleo é calculada atribuindo à palavra de maior peso semântico a porcentagem de $100 \%$ e às seguintes as porcentagens correspondentes, calculadas por regra de três simples (ARAÚJO; CASTRO; SANTOS, 2018; TEIXEIRA et al. 2015).

\section{RESULTADOS E DISCUSSÕES}

O município de Parnaíba é a segunda maior cidade do Estado do Piauí e tem a população estimada de 152.653 habitantes. É uma população relativamente jovem, pois a maior concentração populacional entre os grupos etários é de 20 a 24 anos, ou seja, jovens em idade produtiva, com destaque para o maior número de mulheres, 7.509, em relação aos 7.045 homens. A renda média do(a) trabalhador(a) formal residente na cidade é de 1,7 salário mensal, sendo esses dados referentes a 2010 e 2016, de acordo com o Instituto Brasileiro de Geografia e Estatística (IBGE) (2018).

O censo realizado pelo IBGE em 2010 revelou que a taxa de alunos entre 6 e 14 anos alfabetizados no município girou em torno de $97,5 \%$, ou seja, mais da metade dos alunos na idade se encontravam em alfabetização. Em 2015, o Índice de Desenvolvimento da Educação Básica (Ideb) nos anos iniciais do ensino fundamental foi de 4.3, enquanto nos anos finais foi de 
3.6, demonstrando a diminuição da qualidade desse ensino e aprendizagem na medida em que os alunos progridem de série. O número de matrículas no ensino fundamental em 2017 foi de 21.729 matrículas, porém as inscrições no ensino médio no mesmo período não correspondem nem a um terço das matrículas se comparadas às da etapa anterior, sendo apenas 6.475 matrículas $(29,79 \%)$.

Os dados supracitados revelam que, embora o município tenha ampliado o acesso à escolarização, não é na mesma medida que tem garantido a permanência e conclusão da formação escolar. Embora não sejam fornecidos dados acerca das matrículas na EJA, é possível compreender que os alunos que evadem da escola e até aqueles que nela permanecem, mas em situação de distorção de idade e série, são um público potencial para inserção na modalidade. As informações descritas abaixo tendem a confirmar essa premissa.

O perfil do alunado participante deste estudo corresponde a estudantes matriculados nas etapas 6 e 7 da EJA nos turnos da manhã, tarde ou noite. O perfil foi composto majoritariamente pelo público feminino, sendo $61 \%$ estudantes do sexo feminino e $39 \%$ do sexo masculino. A faixa etária de maior prevalência foi a de 18 a 27 anos, aumentando progressivamente. A idade média foi de 24,64 anos ( $D P=8,75$ ), sendo a idade mínima 18 e a máxima 56 anos. Essa faixa etária dos estudantes da EJA corresponde, portanto, à maior concentração populacional no município, segundo o IBGE (2018), como mostra a Tabela 1 a seguir:

Tabela 1 - Dados sociodemográficos dos estudantes da EJA

\begin{tabular}{|c|c|c|}
\hline \multicolumn{2}{|c|}{ Perfil do alunado da Educação de Jovens e Adultos no Piauí } \\
\hline \multirow{2}{*}{ Sexo } & Variável & $\mathbf{N}-\%$ \\
\hline \multirow{3}{*}{ Idade } & Feminino & $61-61 \%$ \\
& Masculino & $39-39 \%$ \\
\hline \multirow{3}{*}{ Estado civil } & Faixa de 18 a 27 & $73-73 \%$ \\
& Faixa de 28 a 37 & $17-17 \%$ \\
& Faixa de 38 a 47 & $9-9 \%$ \\
Filhos & Faixa de 48 a 57 & $1-1 \%$ \\
& Solteiro & $75-75 \%$ \\
& Casado & $18-18 \%$ \\
& União estável & $7-7 \%$ \\
\hline \multirow{3}{*}{ Profissão } & Nenhum & $62-62 \%$ \\
& Um filho & $19-19 \%$ \\
& De dois a três filhos & $19-19 \%$ \\
\hline
\end{tabular}

Fonte: Pesquisadores (2018).

Obteve-se ainda que grande parte dos estudantes se encontravam solteiros (75\%), casados (18\%) ou em união estável (7\%). Quanto à quantidade de filhos, 62\% não tinham filhos, 19\% tinham apenas um filho e outros 19\% tinham de dois a três filhos. Mais da metade dos estudantes se encontravam fora do mercado de trabalho (56\%), e outra parte, em emprego informal (29\%) ou formal (15\%). Esses dados corroboram com os demais estudos realizados sobre a EJA (ALTHOF; MARTINS FILHO, 2016; NEGREIROS et al., 2017).

As informações sobre o perfil dos estudantes da EJA demonstram o processo de juvenilização do público da modalidade, confirmando o que afirma Pereira e Oliveira (2018), de que há uma 
tendência à concentração de alunos adultos nas etapas iniciais da EJA, enquanto nas etapas finais ascende o número de alunos jovens e adolescentes, e de que esse fenômeno precisa ser compreendido de maneira ampla e não isolada (FRANCHI; GÜNTHER, 2018).

A inserção de jovens e adultos na EJA se dá por diversos fatores, o primeiro consiste na diminuição da idade mínima para 15 e 18 anos, instituída pela LDB, Lei n 9.396/96, para a realização de exames de conclusão, fato descrito anteriormente (RUMMERT, 2007). Juntamente disso, a busca pela agilidade do processo de escolarização levou muitos jovens à EJA, seja pela decisão do próprio aluno, seja por decisão de sua família ou da gestão escolar. Há ainda outros fatores de ordem sociais, como gravidez precoce, vulnerabilidade social, falta de qualidade do ensino e desmotivação (HADDAD, 2007; HADDAD; DI PIERO, 2000).

Ao realizar a análise semântica da palavra-estímulo "escola", pode-se apreender que as representações sociais dos alunos da EJA acerca da escola estão relacionadas à "educação", que obteve peso semântico mais significativo e distância semântica de 100\%, à aprendizagem $(36,5 \%)$, ao estudo $(19,1 \%)$ e também aos professores $(10,4 \%)$ e amigos $(8,3 \%)$, como pode ser observado na Tabela 2 a seguir:

Tabela 2 - Representações de escola construídas por alunos da EJA

\begin{tabular}{|c|c|c|}
\hline \multicolumn{3}{|c|}{ ESCOLA } \\
\hline NR & PS & DSQ \\
\hline Educação & 230 & $100 \%$ \\
\hline Aprendizagem & 84 & $36,5 \%$ \\
\hline Estudos & 44 & $19,1 \%$ \\
\hline Professores & 24 & $10,4 \%$ \\
\hline Amigos & 19 & $8,3 \%$ \\
\hline
\end{tabular}

Fonte: Pesquisadores (2018).

A partir dessas informações, é possível perceber que, para os estudantes da EJA, a escola é representada como um espaço de aquisição de conhecimento, expressa pela evocação das palavras "educação", "aprendizagem" e "estudos". E não somente isso, a pouca distância quantitativa entre as palavras "professores" e "amigos" (demais alunos), que são atores da comunidade escolar, denota que os participantes ancoraram à escola a representação de um espaço profícuo para a socialização.

Corroborando essa compreensão, Naiff e Naiff (2008) e Gomes (2016), ao realizarem estudo com alunos da EJA, destacam que a educação nos tempos atuais é tida como um importante elemento para aquisição de sabedoria e novos conhecimentos, sendo necessária à vida moderna. É comumente atrelada à melhoria das condições de vida e à inserção do mercado de trabalho.

Há, porém, uma relação de ambivalência com que os alunos da EJA representam a escola. Ao passo que a escola é associada ao aprendizado e aos estudos que há muito tempo foram difíceis de alcançar (GOMES, 2016), são as dificuldades decorrentes desse mesmo processo de escolarização, tais como os alunos não se sentirem capazes de aprender, práticas metodológicas tradicionais e que se encerram no comodismo, entre outras, que os desencorajam a continuarem os estudos. O abandono da escola muitas vezes ocorre pelo sentimento de incapacidade e o conjunto de experiências de fracasso escolar, sendo esses fatores preditores da evasão escolar desses alunos em sua trajetória escolar (AMARAL; NEGREIROS; ARAÚJO, 2018; GUZZO, 2014; 
GOMES, 2016; NEGREIROS et al., 2017).

Apesar do exposto, seguindo com a análise semântica das representações da escola, as informações obtidas permitem demonstrar que há uma tendência a uma mudança de conotação atribuída à escola. De acordo com Santos, Pereira e Amorim (2018), percebe-se que a escola na realidade da EJA vem se tonando um espaço social de lazer, de bem viver e afetividade, com condições que muitos dos sujeitos não encontram em casa. A escola é tida como um ambiente que oportuniza troca de relações, o que explica a evocação pelos participantes deste estudo da palavra "amigos". Verificou-se, portanto, que embora a escola seja atrelada primeiramente à educação, na medida em que vai ganhando outros significados, sua representação vai também se deslocando gradativamente da sua ideia primária, a aquisição de conhecimento, para uma compreensão de um espaço social.

Nessa perspectiva, Almeida (2016) e Leite (2007) reiteram a necessidade de entender a escola como um espaço profícuo e estratégico para a formação intelectual do homem coletivo, e um lugar onde se pode compartilhar modos de pensar e agir, compreender as relações sociais historicamente formadas e o lugar de cada jovem e adulto nessas relações. Esse espaço institucional contribui para que os indivíduos transformem sua consciência ingênua em consciência crítica e se constituam enquanto sujeito social e agente de transformação de uma sociedade.

No que tange à análise da palavra-estímulo "educação de jovens e adultos", é indicado que esta é significativamente atrelada à "oportunidade" (ver Tabela 3), com maior peso semântico e distância semântica de 100\%, seguidos de "educação" (33,5\%), "conhecimento" (11,6\%), "formação" (6,4\%) e também "amizades" (5,1\%), como pode ser observado abaixo:

Tabela 3 - Representações sociais da modalidade de Educação de Jovens e Adultos constituídas por alunos da EJA

\begin{tabular}{|c|c|c|}
\hline \multicolumn{3}{|c|}{ Educação de Jovens e Adultos } \\
\hline NR & OS & DSQ \\
\hline Oportunidade & 155 & $100 \%$ \\
\hline Educação & 52 & $33,5 \%$ \\
\hline Conhecimento & 18 & $11,6 \%$ \\
\hline Formação & 10 & $6,4 \%$ \\
\hline Amigos & 8 & $5,1 \%$ \\
\hline
\end{tabular}

Fonte: Pesquisadores (2018).

Denota-se que as representações dos alunos foram objetivadas numa perspectiva da EJA como fomentadora de oportunidades laborais, de obter conhecimento e uma formação, o que é ratificado pelas demais palavras ancoradas que sucedem: educação, conhecimento e formação. A reinserção na educação formal é possivelmente entendida por esses atores sociais como um momento para conclusão do ensino fundamental e médio, bem como sua provável inserção no ensino superior. Tal fato pode ser interpretado como uma forma de realizar metas financeiras e sociais, uma vez que pode possibilitar maiores oportunidades em melhores postos no mercado de trabalho.

Torna-se importante refletir, contudo, que a evocação das palavras "educação", "conhecimento" e "formação" podem indicar ainda que os alunos da EJA atribuem a possibilidade de ascensão social apenas ao ensino e esforço individual, sem levar em conta, todavia, outros 
elementos do seu contexto social, como: desigualdades sociais, escassez de emprego, precariedade dos vínculos trabalhistas e baixa remuneração (GOUVEIA; SILVA, 2015; GUZZO, 2014).

A evocação da palavra "amigos" pode ser compreendida devido à EJA ser um componente que remete à escola, portanto, um espaço que permite a socialização, como descrito anteriormente. A EJA, ao proporcionar formação escolar, propicia não só o preparo para o mercado de trabalho como também colabora para uma satisfação pessoal e para as relações interpessoais inerentes ao espaço escolar (GOUVEIA; SILVA, 2015; SANTOS; PEREIRA; AMORIM, 2018). Outro ponto a se considerar é que a discriminação, a vergonha ou o sentimento de inferioridade em suas relações sociais, por não saberem ler e escrever da maneira esperada, contribuem tanto para o retorno desses escolares como para sua permanência na modalidade, o que pode repercutir nas representações acerca da EJA (GUZZO, 2014).

Quanto ao "futuro", outra palavra-estímulo empregada, obteve-se que a sua representação é associada à "família", que tem o maior peso semântico e distância semântica quantitativa (100\%), e então o "trabalho" (55,4\%), "emprego" $(36,9 \%)$, "casamento" e "filhos", sendo estes dois últimos equivalentes quanto ao DSQ (15,3\%).

Tabela 4 - Representações sociais acerca do futuro construídas por alunos da EJA

\begin{tabular}{|c|c|c|}
\hline \multicolumn{3}{|c|}{ Futuro } \\
\hline NR & PS & DSQ \\
\hline Família & 65 & $100 \%$ \\
\hline Trabalho & 36 & $55,4 \%$ \\
\hline Emprego & 24 & $36,9 \%$ \\
\hline Casamento & 12 & $18,46 \%$ \\
\hline Filhos & 10 & $15,3 \%$ \\
\hline
\end{tabular}

Fonte: Pesquisadores (2018).

O futuro é prontamente representado pela família para os participantes deste estudo. Ao buscar compreender o sentido pelo qual os alunos associam o futuro à família, é importante considerar as relações de ambivalência que podem emergir, pois, se ao passo que a auxiliar a família é um dos motivos apontados para saída da escola, este é também um dos motivos para o seu retorno. Naiff e Naiff (2008) afirma que a necessidade de subsistência e de contribuir com a renda é um dos motivos mais apontados para justificar o abandono da escola; a necessidade de melhorar as condições de vida e familiares e os anseios por compor uma nova família são também alguns dos fatores determinantes para o retorno à escola.

O trabalho e o emprego são ainda inseridos nas representações sociais de futuro por parte dos alunos da EJA. Por um lado, o trabalho tem um papel duplo na vida desses escolares, isso porque a saída da escola para buscar trabalho tem por consequência a baixa escolarização do trabalhador e o empobrecimento da qualidade da mão de obra qualificada. Por outro lado, o mercado de trabalho moderno vem exigindo cada vez mais mão de obra qualificada, restando aos que não correspondem às suas exigências os empregos de baixa remuneração (NAIFF; NAIFF, 2008; GUZZO, 2014; SANTOS; PEREIRA; AMORIM, 2018; NASCIMENTO et al. 2018). Desse modo, se outrora a dimensão social do trabalho fez com que muitos dos jovens e adultos deixassem a escola, agora os leva a retomar a escolarização. 
Em estudo recente, Negreiros et al. (2017) ressalta que o trabalho tem um significado para além da retribuição financeira, ele está aliado também ao ganho de autonomia, reconhecimento da família e realização pessoal e profissional. A conquista de um bom emprego não tem um valor social reduzido, mas culminará na melhoria das condições de vida e oportunidades futuras.

Santos, Pereira e Amorim (2018) evidenciam ainda a heterogeneidade do alunado que compõe a EJA. Dessa forma, é possível identificar não só alunos que estão inseridos no mundo do trabalho, mas aqueles que não fazem nenhum tipo de curso profissionalizante e não participam de nenhuma atividade extraescolar - para esses, o trabalho e emprego podem ser aspirações futuras.

Com a juvenilização do público da EJA, uma parcela dos alunos é solteira e, com isso, ao representarem o futuro, ancoram-no a "casamento", uma das palavras evocadas, a possibilidade de composição de novas configurações familiares ou reformulação das já existentes (PEREIRA; OLIVEIRA, 2018). Em contrapartida, outro conteúdo evocado ao tratar de futuro foram os filhos, indicando que os jovens e adultos da EJA que têm filhos, ao reconhecer que a baixa escolarização pode afetar escolarização dos filhos, tendem a retomar a escola para ajudá-los (GOMES, 2015; GUZZO, 2014).

As representações acerca do futuro estão em acordo ao que Negreiros et al. (2017) afirma: que os alunos da EJA, ao perceberem que sua condição de vida atual não é o ideal, projetam para si um novo futuro. Seus projetos voltam-se, com isso, para o amparo a suas famílias e ao desenvolvimento pessoal e profissional, que lhes permitam melhorias financeiras e a mudança de seu lugar social.

De modo geral, as RSs dos estudantes da EJA revelam que eles têm a escola como um espaço de aquisição de conhecimento e socialização e que veem a EJA como uma oportunidade de concluir sua formação básica e ingresso no ensino superior; nesse sentido, têm expectativas de que no futuro consigam melhorar as condições de vida, familiares e profissionais. Além do exposto, ao abordar essa temática à luz dessa teoria psicológica, o presente estudo contribui para o estado da arte, uma vez que permite a análise de diferentes aspectos psicossociais que envolvem a EJA, assim como vem ocorrendo por meio da obra A Psicologia Escolar e a Educação de Jovens e Adultos (NEGREIROS; CAMPOS, 2019). Essa é a primeira obra que aborda a interface Psicologia e EJA e, com isso, inaugurou em 2019 a discussão sobre como a Psicologia Escolar pode contribuir com essa modalidade educacional.

\section{CONSIDERAÇÕES FINAIS}

O presente estudo, que buscou a apreensão das representações sociais de estudantes da EJA acerca da escola, da própria modalidade "educação de jovens e adultos" e do futuro, atingiu o objetivo ao qual se propôs e, a partir dele, puderam-se revelar os sentidos partilhados por este grupo quanto ao fenômeno estudado.

Observou-se que o público participante consistiu majoritariamente em alunos jovens entre 18 e 27 anos, indicando a juvenilização dos estudantes da EJA. No que se refere à escola, foi evidenciado que há uma tendência dos alunos de representá-la como um ambiente que Ihes proporcione aquisição do conhecimento, ensino e novas aprendizagens, mesmo muitos tendo enfrentado situações adversas em sua trajetória escolar. Além disso, a escola também é representada como um espaço de socialização, mostrando que, para esses estudantes, a escola também desempenha um papel social e possivelmente de formação humana. 
A EJA enquanto modalidade é representada como uma oportunidade de obter conhecimento e alcançar uma formação, seja a conclusão da educação básica, seja o possível ingresso na educação superior. Enquanto espaço escolar, a EJA é também comumente atribuída a um ambiente de socialização. Com relação ao futuro, os estudantes tendem a objetivar a este a possibilidade de melhorias nas condições de vida, da família e também de trabalho. Eles têm a expectativa de que, com a escolarização, novas oportunidades de emprego surgirão e, com isso, também as melhorias financeiras. Além disso, atribuem ao futuro a possibilidade de comporem novas configurações familiares.

De modo geral, a partir do estudo das RSs de estudantes da EJA, foi possível verificar que, para esses alunos, a educação é um possível meio de ascensão social. Os alunos representam a escola e, por conseguinte, a modalidade da EJA, a possibilidade de adquirir conhecimento, novas aprendizagem e alçar seus projetos de vida, mesmo tendo passado por condições adversas, seja porque não tiveram acesso à educação, seja por dificuldades decorrentes do processo de escolarização. Apesar disso, faz-se necessário ainda o estudo de outros elementos que se relacionam à escolarização para o maior aprofundamento das informações obtidas, tais como: práticas pedagógicas utilizadas e as RSs dos demais atores da escola, como professores, diretores e outros.

Sugere-se, com isso, que sejam realizados estudos longitudinais posteriormente, de modo a retratar a RS de outros estudantes e também dos demais atores sociais em outros contextos e realidade, a fim de promover o conhecimento acerca da modalidade e do seu público e, assim, fomentarem-se políticas públicas com base na realidade psicossocial brasileira.

\section{REFERÊNCIAS}

ALMEIDA, A. A EJA: uma educação para o trabalho ou para a classe trabalhadora? Revista Brasileira de Educação de Jovens e Adultos, Salvador, v. 4, n. 8, 2016.

AMARAL, E. B.; NEGREIROS, N.; ARAÚJO, L. F. Medicalização da Educação: representações sociais. In: MEDEIROS, E. D.; ARAÚJO, L. F.; COUTINHO M. P. L.; ARAÚJO, L. S. (Org.). Representações Sociais e práticas psicossociais. Curitiba: CMRV, 2018. p. 281-98.

ALTHOF, F.; MARTINS FILHO, L. J. O mapeamento do estudante para o ensino médio da educação de jovens e adultos na rede estadual de ensino do estado de Santa Catarina: cenários e perspectivas. Revista Brasileira de Educação de Jovens e Adultos, Salvador, v. 4, n. 8, 2016.

ARAÚJO, L. F; CASTRO, J. L. C.; SANTOS, J. V. O. A família e sua relação com o idoso: um estudo de representações sociais. Revista Psicologia em Pesquisa, Juiz de Fora, v. 12, n. 2, 2018.

BRASIL. Conselho Nacional de Educação. Resolução n. 1, de 5 de julho de 2000. Estabelece as Diretrizes Curriculares Nacionais para a Educação de Jovens e Adultos. Diário Oficial da União, Brasília, 19 jul. 2000. Disponível em: http://portal.mec.gov.br/cne/arquivos/pdf/CEB012000.pdf. Acesso em: 8 dez. 2018.

BRASIL. Conselho Nacional de Educação. Parecer n. 6, de 4 de abril de 2010. Institui Diretrizes Operacionais para a Educação de Jovens e Adultos - EJA. Diário Oficial da União, Brasília, 4 abr. 2010. Disponível em: http://portal.mec.gov.br/index.php?option=com_docman\&view=download\&alias=5366-pceb00610\&category_slug=maio-2010-pdf\&ltemid=30192. Acesso em: 8 dez. 2018

BRASIL. Lei n. 9.394, de 20 de dezembro de 1996. Estabelece as diretrizes e bases da educação nacional. Brasília-DF, 1996. Disponível em: http://www.planalto.gov.br/ccivil_03/Leis/L9394.htm. Acesso em: 8 dez. 2018. 
CAMARGO, B. V.; SCHLOSSER, A.; GIACOMOZZI, A. I. Aspectos epistemológicos do paradigma das representações sociais. In: MEDEIROS, E. D.; ARAÚJO, L. F.; COUTINHO, M. P. L:; ARAÚJO, L. S. (Org.). Representações Sociais e práticas psicossociais. Curitiba: CMRV, 2018. p. 153-66.

CARLOS, K. P. T.; SANTOS, J. V.O.; ARAÚJO, L. F. Representações sociais da velhice LGBT: estudo comparativo entre universitários de Direito, Pedagogia e Psicologia. Psicogente, Barranquilla, v. 21, n. 40, p. 297-320, 2018.

DI PIERRO, M. C. Notas sobre a redefinição da identidade e das políticas públicas de educação de jovens e adultos no Brasil. Educação \& Sociedade, Campinas, v. 26, n. 92, 2005.

FRANCHI, S.; GÜNTHER, M. C. C. Juvenilização da EJA: repercussões na Educação Física. Motrivivência, Florianópolis, v. 30, n. 53, p. 209-25, 2018.

FONTANELLA, B. J. B.; LUCHESI, B. M.; SAIDEL, M. G. B.; RICAS, J.; TURATO, E. R.; MELO, D. G. Amostragem em pesquisas qualitativas: proposta de procedimentos para constatar saturação teórica. Cadernos de Saúde Pública, Rio de Janeiro, v. 27, n. 2, p. 388-94, 2011.

GOMES, A. C. Os significados que os alunos da EJA têm em relação à instituição escolar. Interagir: pensando a extensão, v. 20, p. 1-21, 2015.

GOUVEIA, D. D. S. M.; SILVA, A. M. T. B. D. A formação educacional na EJA: dilemas e representações sociais. Ensaio Pesquisa em Educação em Ciências, Belo Horizonte, v. 17, n. 3, p. 749-67, 2015.

GUZZO, R. S. L. As contradições dos bastidores da Educação de Jovens e Adultos: elementos da história de vida e perspectiva de mudança. In: GUZZO, R. S. L. Psicologia Escolar: desafios e bastidores da educação pública. Campinas, SP: Alínea, 2014.

HADDAD, S. A ação de governos locais na educação de jovens e adultos. Revista Brasileira de Educação, Rio de Janeiro, v. 12, n. 35, p. 197-211, maio/ago. 2007.

HADDAD, S.; DI PIERRO, M. C. Escolarização de jovens e adultos. Revista Brasileira de Educação, Rio de Janeiro, n. 14, p. 108-30, maio/ago. 2000. Disponível em: http://www.scielo.br/pdf/rbedu/n14/n14a07. pdf. Acesso em: 8 dez. 2018.

IBGE. Parnaíba. Brasília: IBGE, 2018. Disponível em: https://cidades.ibge.gov.br/brasil/pi/parnaiba/ panorama. Acesso em: 8 dez. 2018.

JODELET, D. Représentations sociales: un domaine en expansion. In. JODELET, D. Les représentations sociales. Paris: PUF, 1989, pp. 31-61.

LEITE, S. A. A construção da escola pública democrática: algumas reflexões sobre a política educacional. In: SOUZA, B. P. Orientação à queixa escolar. São Paulo: Casa do Psicólogo, 2007.

LIBÂNEO, J. C. O dualismo perverso da escola pública brasileira: escola do conhecimento para os ricos, escola do acolhimento social para os pobres. Educação e Pesquisa, São Paulo, v. 38, n. 1, p. 13-28, 2012.

MOSCOVICI, S. Representações sociais: investigações em psicologia social. 5. ed. Petrópolis: Vozes, 2007.

NAIFF, L. A. M.; NAIFF, D. G. M. Educação de jovens e adultos em uma análise psicossocial: representações e práticas sociais. Psicologia \& Sociedade, v. 20, n. 3, 2008.

NASCIMENTO, A. W. S.; CORDEIRO, Y. E. M.; TAVARES, F. B.; BELTRAO, N. E. S. Educação e sociedade: o papel das Políticas de Ensino Médio na formação de estudantes em escola pública da Amazônia Paraense. Interações, Campo Grande, MS, v. 19, n. 2, p. 417-28, jan./mar. 2018. 
NEGREIROS, F.; SILVA, C. F. C.; SOUSA, Y. L. G.; SANTOS, L. B. Análise psicossocial do fracasso escolar na Educação de Jovens e Adultos. Psicologia em Pesquisa, v. 11, n. 1, 2017.

NEGREIROS, F.; CAMPOS, H. R. A Psicologia Escolar e a Educação de Jovens e Adultos. Campinas: Alínea, 2019.

PEREIRA, J. V. Tendências históricas da educação dos jovens e adultos no Brasil: da subordinação a tentativas de emancipação. Educativa, v. 17, n. 1, p. 175-200, 2014.

PEREIRA, T. V.; OLIVEIRA, R. A. A. Juvenilização da EJA como efeito colateral das políticas de responsabilização. Estudos em Avaliação Educacional, v. 29, n. 71, p. 528-53, maio/ago. 2018.

RUMMERT, S. M. A educação de jovens e adultos trabalhadores brasileiros no século XXI. O "novo" que reitera antiga destituição de direitos. Sísifo: Revista de Ciências da Educação, Porto, n. 2, p. 35-50, jan./ abr. 2007. Disponível em: http://sisifo.fpce.ul.pt. Acesso em: 10 dez. 2018.

SANTOS, M. F. S.; MORAIS, E. R. C.; NETO, M. L. A. A produção científica em representações sociais: análise de dissertações e teses produzidas em Pernambuco. Psico, v. 43, n. 2, p. 8, 2012.

SANTOS, J. S.; PEREIRA, M. V; AMORIM, A. Os sujeitos estudantes da EJA: um olhar para diversidade. Revista Internacional de Educação de Jovens e Adultos, v. 1, n. 1, 2018.

SILVA, M. M. Desafios Intersetoriais: possibilidades de diálogos e a Educação de Jovens e Adultos. Curitiba: Appris, 2017.

TEIXEIRA, I. N.; DIAS, L. C.; CASTRO, T. L.; FREITAS, F. R. S.; ARAÚJO, L. F. Resiliência na velhice: uma análise das representações sociais dos idosos. Kairós: Gerontologia, v. 18, n. 4, p. 215-32, 2015.

\section{Sobre os autores:}

Carolina Martins Moraes: Mestra em Psicologia no Programa de Pós-Graduação em Psicologia pela Universidade Federal do Piauí (UFPI). Psicóloga. Pesquisadora pela Fundação de Amparo à Pesquisa do Estado do Piauí (Fapepi). E-mail: carolinamm12@gmail.com, Orcid: https://orcid.org/0000-0003-3398-7000

Ludgleydson Fernandes de Araújo: Doutor em Psicologia pela Universidad de Granada (Espanha), com período sanduíche na Università di Bologna (Itália). Mestre em Psicologia e Saúde pela Universidade de Granada (Espanha); mestre em Psicologia Social e especialista em Gerontologia pela Universidade Federal da Paraíba (UFPB). Psicólogo. Professor orientador do Programa de Pós-Graduação (Stricto Sensu) em Psicologia da Universidade Federal do Piauí (UFPI). Bolsista de Produtividade PQ-2 em pesquisa pelo CNPq. Coordenador do GT da Associação Nacional de Pesquisa e Pós-Graduação em Psicologia (Anpepp) "Relações Intergrupais: Preconceito e Exclusão Social”. E-mail: ludgleydson@yahoo.com.br, Orcid: https://orcid.org/0000-0003-4486-7565

Fauston Negreiros: Doutor e mestre em Educação pela Universidade Federal do Ceará. Psicólogo pela Universidade Estadual do Piauí. Professor-pesquisador adjunto IV do Departamento de Psicologia, do Programa de Pós-Graduação (Stricto Sensu) em Psicologia e do Programa de Pós-Graduação (Stricto Sensu) Ciência Política da Universidade Federal do Piauí (UFPI). E-mail: faustonnegreiros@ufpi.edu.br, Orcid: https://orcid.org/0000-0003-2046-8463 
